\title{
Editorial
}

\section{Editor's introduction to the special section: Feminism and psychoanalysis: Conversations across generations}

\section{Lynne Layton}

Massachusetts Institute for Psychoanalysis, 253 Mason Terrace, Brookline, MA 02446, USA.

E-mail: layton@rcn.com

\begin{abstract}
I introduce four papers first presented at the 2014 APCS conference in a panel on psychoanalysis and feminism. Featuring feminists from different generations, these papers take up some generational conflicts within feminism and discuss what psychoanalysis offers and fails to offer to feminist analysis and activism. They caution against feminist tendencies toward moralism and toward universalizing positions of privilege. The authors engage as well with what their encounters with other generations have taught them and with what they want to pass on.

Psychoanalysis, Culture \& Society (2016) 21, 221-222.

doi:10.1057/s41282-016-0031-y
\end{abstract}

Keywords: feminism; psychoanalytic feminism; generation; difference; activism

In the June 2015 issue of Psychoanalysis, Culture \& Society, we presented a special section commemorating the 40th anniversary of Juliet Mitchell's 1974 text, Psychoanalysis and Feminism. In that issue, we featured the voices of feminists from different generations. Putting those voices into conversation illuminated differences both in the authors' experiences of feminism over time and in their relations to different versions of psychoanalysis. For the 2014 APCS conference, several of us organized a panel titled Psychoanalysis and Feminism: Recollection, Repetition, and Working Through. Here again we set as our task a conversation across generations that would address, psychoanalytically, what it has meant and what it might currently mean to be, as one contributor calls it, a "good-enough" feminist. Our contributors, Janice Haaken, Margeaux Feldman, Angie Voela, and Katie Gentile, take up their own encounters, as feminist activists and 
feminist academics, with other generations and other circulating definitions of feminism.

Critical of historically repeating feminist tendencies toward moralism, particularly regarding questions of sexuality and desire, both Haaken and Feldman appeal to psychoanalysis to keep open the complexity of sexual dynamics and of differences in desire. While Feldman focuses on individual difference, Haaken takes up feminist group dynamics over time and speaks of the necessity for activists to be able to weather the projections of anti-feminists without collapsing or retaliating. Within the movement, she cautions against falling prey to simplistic narratives that figure women as morally superior, pure victims facing pure perpetrators. Also arguing against a moralistic feminism, Feldman writes of willful third wavers who refuse to cede on their desire, even when that desire is not deemed politically correct or feminist enough by other generations of feminists.

In her plea to feminists to refrain from hierarchizing forms of desire, Feldman cites Ahmed's call to embrace states within which relations among women are not harmonious, states of non-attunement. Both Voela and Gentile write of their own encounters with non-attunement. They struggle to bring their own histories of feminist activism and theorizing into their encounter with the very different realities of their students, who often hold quite ambivalent attitudes toward feminism. In their different ways, these pieces evoke the complexity of time, of what it means and has meant to take up a feminist identity, of encounters with difference within and across generations, and of what psychoanalysis both offers and fails to offer to the project of creating and living feminist ethics.

\section{About the Author}

Lynne Layton is a co-editor of Psychoanalysis, Culture \& Society and a supervising analyst at the Massachusetts Institute for Psychoanalysis. 